Vietnam Academy of Science and Technology
Vietnam Journal of Earth Sciences
Website:http://www.vjs.ac.vn/index.php/jse

\title{
Study of Subsidence detection by DinSAR and evaluation of some factors to the outcome
}

\author{
Tran Van Anh ${ }^{1}$, Tran Quoc Cuong ${ }^{* 2}$, Nguyen Duc Anh ${ }^{2}$, Dang Vu Khac \\ ${ }^{1}$ University of Mining and Geology, Hanoi, Vietnam \\ ${ }^{2}$ Institute of Geological Sciences, VAST, Hanoi, Vietnam \\ ${ }^{3}$ Hanoi National University of Education, Hanoi, Vietnam
}

Accepted 25 December 2015

\section{ABSTRACT}

The paper focuses on determining the subsidence by Differential Interferometric Synthetic Aperture Radar (DInSAR) using two methods (Two-pass and Three-pass) and assessing the effect of some error sources to the results. Errors effecting the result include atmospheric, phase due to signal-to-noise ratios, number of looks, pixel misregistration and baseline decorrelation; however, especially significant is (Digital Elevation Model) DEM error. We proved that application of DEM with low precision would create virtual subsidence. The experiment area is Hanoi city, data was Envisat ASAR image, C band with the wavelength of 5.6cm. By using SARscape software for processing, with Two-pass method a virtual subsidence was found at one site in northern part of Hanoi near the Red River (Song Hong). With the Three-pass method this subsidence site did not occurred. Besides, results of surface subsidence detection using DInSAR methods were compared with those measured directly from monitoring stations located close to water supplying wells. As a result, data acquired from Ha Dinh and Thanh Cong stations were closely distributedto those determined by DInSAR method. Unfortunately, the subsidence data acquired by direct measurement had been conducted continuously only from 2000 to 2003 instead to 2005; whereas the Envisat ASAR subsidence data are available only from 2003 to 2004. Therefore, combination of data of direct measurement at Ha Dinh and Thanh Cong stations, and DInSAR processing should provide a linear correlation. . The study proves using DInSAR with Three-pass method would provide more reliable result as compared to the Two-pass method even with a limited amount of images.

Keyword: land subsidence, interferometry, DInSAR, Envisat ASAR.

C2015Vietnam Academy of Science and Technology

\section{Introduction}

SAR interferometry is an established technique based on combining two synthetic aperture radar (SAR) images of the same scene acquired from different viewpoints and different time or from two antennas mounted on the spacecraft. Graham (1974) was the first to introduce synthetic aperture radar (SAR) for topographic mapping using data

${ }^{*}$ Corresponding author, Email: tqcuong@igsvn.ac.vn supplied by the first civilian remote sensing satellite SeaSAT. Zebker and Goldstein (1986) presented the first results with side looking airborne in 1986 that mounted two SAR antennas on an aircraft with $11.1 \mathrm{~m}$ from each other. Since then there were many Interferometric SAR (InSAR) systems were designed and constructed and consequently, variety of application were generated such as surface deformation studies (Massonet et al., 1993), or ice flow analysis Goldstein et al., 1993). With the surface 
T.V. Anh, et al./Vietnam Journal of Earth Sciences 37 (2015)

deformation research, the differential SAR Interferometry (DInSAR) is commonly used. This method using two images is termed as "Two pass" or three, four images, termed as "Three pass" or "Four pass". DInSAR was first applied on Seasat images at Jet Propulsion Laboratory JPL to measure small elevation changes over larger swaths $50 \mathrm{~km}$ in Imperial Valley, California (Gabriel and Goldstein, 1989). Since then many scientists have applied this technique for measurement of geographical process including land subsidence in mining areas (Ferreti et al., 2000), landslides in mountainous areas (Rott et al., 2000) and detection of volcanic deposit, etc.

However, the DInSAR method for subsidence detection exposed its disadvantages, these are errors from atmospheric influences, the baseline of image pairs and the influence of the digital terrain model (DTM) that is used for eliminating the topographic phase in DInSAR if using Two-pass method. Because of these reasons there were some new approaches that have been tried to remove the errors, such as Persistent ScattererInterferometric Synthetic Aperture Radar PSInSAR which was the first applied in 2000 by Ferreti et al. or Multitemporal Interferometric Synthetic Aperture Radar MT-InSAR that has been used in research of Hooper et al. (2007). Some other researchers investigated the error by using PSInSAR method (Colesanti et al., 2003; Dehls and Nordgulen, 2003). The study by Colesanti et al. (2003) monitored the fault creep along the Hayward Fault in California. In this case, Colesanti et al. (2003) estimated the line of sight (LOS) directional displacement rate due to fault creep using PSInSAR technique. The projection of LOS displacement along the fault direction was compared with creep meter records with less than 10 percent error. Dehls and Nordgulen (2003) monitored land subsidence in Oslo in Norway caused by tunnel construction and related groundwater drainage. The subsidence of this study area was surveyed using leveling and the field records were compared to PSInSAR results. The PS-InSAR or MT-InSARtechniques has proved to be effective in many studies and is versatile to various surface deformation monitoring tasks. However, the limitations of PSInSAR technique is the numbers of images to be used are numerous (at least 15 images). Thus in the areas with limited number of images these methods cannot be used. Our studies focus on the urban area during the stage between 2000 and 2005 in Hanoi. At this stage there were no variety radar images to choose, the type of image being studied was Envisat ASAR, with very few images.

There have been a few investigations using DInSAR and MT-InSAR methods for subsidence detection in Hanoi. Raucoules and Carnec (1999) used ERS-1/2 SAR C band data for detecting the subsidence over the urban area with several pairs of interferometric images. They detected signatures of ground movement about $1.5 \mathrm{~cm}$ in noisy differential interferograms. Our research (e.g. Tran et al 2007) employed JERS-1 L band with "Three pass" method in the period of 1995 1998. The distributions of subsidence were detected in the southern part of city with $2 \mathrm{~cm}$ to $3 \mathrm{~cm}$ per year, and the around of West Lake (Ho Tay). This research proved the capabilities of "Three pass" method for detecting subsidence. Nevertheless, this study did not assess some influential factors to the results acquired by DInSAR. Recently the research of Dang et al. (2014) with utilizing MT-InSAR for land subsidence detection in the Hanoi area by ALOS data. In this research, there were 21 SAR image scenes acquired in L-band used. The subsidence was distributed by PS points, especially the subsidence caused by buildings or roads.

In the period of 2000 to 2005, number of construction sites were increased, the ground water was also extracted more, which was the major cause of subsidence. In this study we detect land subsidence in Hanoi using "Two pass" and "Three pass" differential interferometry method with a limited data set of Envisat ASAR from the year 2003 to 2004. We evaluate the accuracy of the results provided by "Two pass" and "Three pass" methods. Besides, errors occurred by DInSAR method and phase were analyzed in order to propose the optimal method and data set for subsidence detection.

\section{Overview of DInSAR and the sources of error}

\subsection{Differential interferometry $S A R$}

There are two ways of implementing differential interferometry. One is using an external digital elevation model (DEM) and other is using extra radar images to simulate the topography. Method using external digital elevation model requires only two radar images, 
assuming the deformation was occurred during these acquisitions, and is known as two-pass method. The second method does not require any other information than the radar data. The topographic reference here is created by the additionally acquired radar images, third or fourth, and respectively the method is called three-pass and four-pass methods. In both cases difference is made between two interferograms, one of which contains only topography (topographic pair), while the other containing both topography and deformation (deformation pair). The resulted differential fringes represent the half wavelength displacement in the direction of radar line of sight. By counting the appeared fringes, the quantity of deformation can be determined. However, atmospheric influences in this case study cannot be distinguished from the deformation signal.

\subsection{Two-pass method}

In Two-pass methodDEM is used as synthetic interferogram simulating topographic phase. Before subtracting from the real interferogram, which contains both topography and deformation, elevation model has to be converted to the radar slant range azimuth coordinates and scaled using the baseline. The advantages of this method are that it requires only once unwrapping air. The only limitation is the availability of DEM of interested area. This method is considered as fast one but the error of DEM effects to deformation model. DEM error will produce a phase error in the interferogram (Sowter et al., 2005) which is illustrated by equation (1)

$$
\mathbf{E}_{\phi}=\mathrm{E}_{\mathrm{DEM}} / \mathrm{h}_{\mathrm{a}}
$$

where $\mathrm{E}_{\mathrm{DEM}}$ : error in DEM,

$h_{a}:$ is altitude of ambiguity

\subsection{Three-pass method}

In three-pass method three SAR scenes will be needed, but no DEM. But three images must be acquired in a such way that in their combination one pair contains only topographic information, thus temporal separation is smaller and another pair contains both topographic and deformation information, thus temporal baseline is larger, spanning event time. As shown in Figure 1 if three images were acquired in satellite positions $\mathrm{S} 1, \mathrm{~S} 2$ and S3 and it is assumed that there are no movements having been occurred between two acquisitions (S1 and S2, interferogram generated from them will be used as topographic reference. Displacements are supposed to be occurred between the first and third images acquisitions (S1 and S3). Then, to get the differential interferogram, the topographic phase of the first pair should be subtracted from the phase of the second pair, which contains both topography and deformation contributions. But as depicted in the Figure 1 two interferograms has two different baseline length Band ' $\mathrm{B}$ ', and baseline orientations $\alpha$, and $\alpha$ ' due to the different orbits. However, two interferograms share one common image.

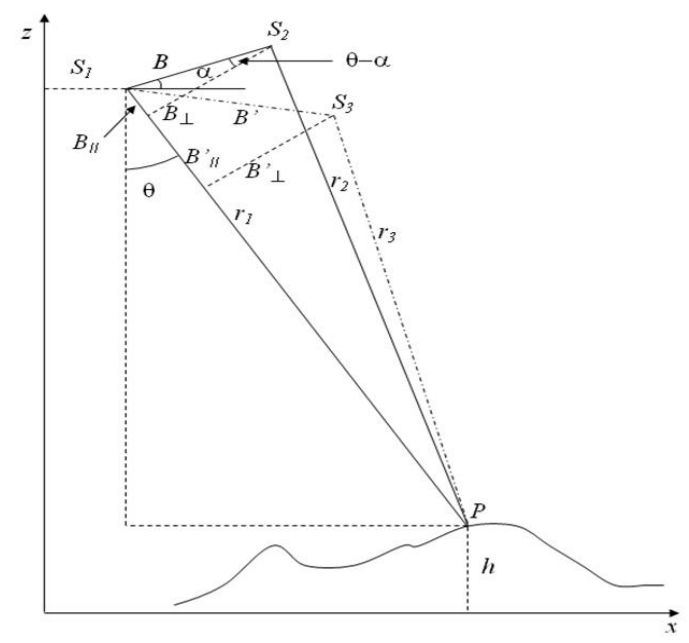

Fig. 1. The geometry of 3-pass differential interferometry

In Equations (Kampes B) shown below, in order to bring them in one geometry one of them (topographic interferogram) should be scaled by the ratio of two perpendicular baselines. This method can be applied only if both the topographic pair and the deformation pair have a common image.

$$
\phi^{\prime}=\phi \frac{\mathrm{B}_{\perp}}{\mathrm{B}_{\perp}^{\prime}}-\frac{4 \pi}{\lambda} \Delta r
$$

Then the phase caused by the deformation is equal (2)

$$
\phi_{\Delta r}=\phi^{\prime}-\phi \frac{\mathrm{B}_{\perp}}{\mathrm{B}_{\perp}^{\prime}}
$$

$\Phi$ : is the topographic phase;

$\Phi^{\prime}$ : is the phase including deformation phase;

$B \perp$ : is the perpendicular base line of topographic pair; 
T.V. Anh, et al./Vietnam Journal of Earth Sciences 37 (2015)

$B_{\perp}^{\prime}$ : is the perpendicular base line of deformation pair.

\section{Factors influencing to the DInSAR}

The interferometric phase can be affected by many decorrelation effects (factors), which can be categorized as follows: (1) Phase noise sources, and (2) Atmospheric effect. These effects decrease the suitability of radar interferometry for surface deformation detection or DEM generation.

\subsection{Phase noise source}

The quality of interferogram at each pixel is strongly dependent on the degree of data coherence. There are, however, several sources that contribute to the loss of coherence between radar echoes and limit the accuracy of SAR interferometry. Three main sources of decorrelation are:

- Thermal noise

- Baseline or geometric decorrelation

- Temporal decorrelation

\subsection{Atmospheric effect}

It is most likely that conditions in the atmosphere are not identical as the images are acquired at different times. Therefore, the length of the measured ray path between the sensor and the ground can change due to the time delay caused by any differences in the tropospheric and ionospheric disturbances. Any atmospheric heterogeneity will appear as a phase distortion in an interferogram and thus limit the confidence of the results. Hanssen and Feijt (1996) quantitatively evaluate the atmospheric effects on SAR interferometry using an existing tropospheric model. A quantitative assessment of the influence of three major atmospheric parameters, such as pressure, relative humidity and temperature on the interferometric phase has been derived.

According to Zebker et al. (1997), interferograms derived from repeat-pass radar interferometry can be affected due to the time and space variation of atmospheric water vapor. Furthermore, variation of pressure and temperature do not induce distortion significantly as they are more evenly distributed through an interferogram than the wet troposphere term. Zebker et al. (1997) states that dry regions have fewer variations than wet regions. Although night time acquisition can reduce atmospheric artifacts more than daytime, due to more quiescent vegetation and a statistically more stable atmosphere at night (Massonnet and Feigl, 1998), the user has no control over the acquisition time for any given region on the Earth.

The ionosphere effect is extremely difficult to remove from the radar observation. Using GPS technology, and based on the dispersive nature of the ionosphere, the combination of phase measurements at two different frequencies could eliminate the ionospheric contribution. This approach would require two radar images acquired simultaneously at different frequencies. Unfortunately, such a radar system does not exist. However, according to Gray et al. (2000) the ionospheric disturbance influences radar interferometry causing an azimuth offset which results in azimuth shift modulations at a kilometer scale for C-band wavelength.

\section{DInSAR error}

If we consider the quality of a single synthetic aperture radar (SAR) interferogram, it is clear that there are many potential sources of error. In addition to atmospheric errors, there are phase errors due to signal-to-noise ratios, number of looks, pixel misregistration and baseline decorrelation, as presented above.

If we have three images spanning a deformation event, we can generate two interferograms, one containing no deformation (referred to here as the TOPO interferogram) and the other containing the deformation (similarly referred to as the DEFO interferogram). Consider that there are intrinsic errors in the interferometric phase of an amount $\varepsilon$. The Baseline Ratio method, defined by Zebker et al. 1994, is the standard 3Pass method and assumes that the differential phase due to the deformation, $\delta \phi_{3}$, is given by:

$$
\delta \phi_{3}=\delta \phi+\varepsilon^{D E F O}-\frac{B_{\perp}{ }^{D E F O}}{B_{\perp}^{T O P O}} \varepsilon^{T O P O}
$$

Where $B_{\perp}{ }^{T O P O}$ and $B \perp{ }^{D E F O}$ are the perpendicular components of the orbital baselines of the topographic and deformation pairs, respectively and $\delta \phi_{3}$ is the differential phase related to the 
Vietnam Journal of Earth Sciences 37 (2015) 344-354

deformation only. A standard 2-Pass method proceeds by simply subtracting a simulated phase component, using the DEM, from the actual component giving:

$$
\delta \phi_{2}{ }^{D E F O}=\delta \phi+\varepsilon^{D E F O}-\delta \phi_{\tau}^{D E F O}
$$

where the phase error $\delta \phi_{\tau}$ caused by a height error of $\tau$ is given by Zebker et al.(1994) as:

$$
\delta \phi_{\tau}=\frac{4 \pi B_{\perp}}{\lambda \rho \cos \theta} \tau
$$

Comparing (4) with (5) it is clear that the difference between 2-Pass and 3-Pass DInSAR, in terms of errors, lies in the final term alone. Therefore, any improvements will be based on the characteristics of those errors.

\section{Data and processing}

\subsection{Study area and data}

Hanoi, the capital of Vietnam, is located at latitudes $20^{\circ} 53^{\prime}-21^{\circ} 23^{\prime} \mathrm{N}$ and longitudes $105^{\circ} 44^{\prime}$ - $106^{\circ} 02^{\prime} \mathrm{E}$ in the plain of North Vietnam. Hanoi is surrounded by six provinces; Thai Nguyen in the north, Bac Ninh and Bac Giang in the east, Hung Yen in the southeast, Ha Tay in the south and southwest, and Vinh Phuc in the west. There are many rivers flowing eastwards to the sea that is a convenient transport cluster for all the Northern provinces. Because Hanoi is in a river delta, most of the Hanoi area is flat with elevations below $20 \mathrm{~m}$ except the northern mountainous part up to $400 \mathrm{~m}$ height. The general topography is sloped gently from North-West to South-East in accordance with trend of Red river's flow. In the center of city, the elevation is about $8 \mathrm{~m}-12 \mathrm{~m}$, while the southern part of the city the elevation is about $3 \mathrm{~m}-5 \mathrm{~m}$. Figure 2 shows the location of Hanoi in the Red River Delta.

The data set is Envisat ASAR raw images, C band (see the table 1), beside that we used Shuttle Radar Topography Mission SRTM DEM 90m for Two pass and accurate Three pass. Precise orbits, provided by the ESA WEB site were used throughout for image focusing. SARScape software was used for all ENVISAT and precise orbit data processing and interferogram formation. Figure 3 shows the overall view of Envisat ASAR 2004 January $10^{\text {th }}$.

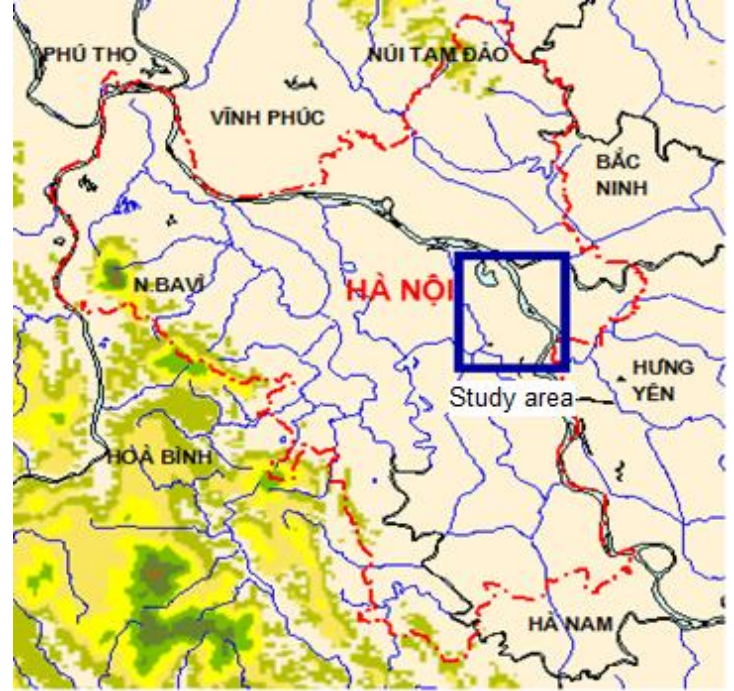

Fig. 2. The location of Hanoi in the Red River Delta

Table 1. Envisat ASAR data set

$\left.\begin{array}{lll}\hline \begin{array}{l}\text { No } \\ 1\end{array} & \begin{array}{l}\text { Date }(\mathrm{yr} / \mathrm{m} / \mathrm{d}) \\ 2003 / 12 / 06 \\ 2\end{array} \\ 3 & \begin{array}{l}2004 / 1 / 10 \\ 4\end{array}\end{array}\right\}\left\{\begin{array}{l}1^{\text {st }} \text { Pair } \\ 2^{\text {nd }} \text { Pair } \\ 3^{\text {rd }} \text { Pair } \\ 4^{\text {th }} \text { Pair }\end{array}\right\}$

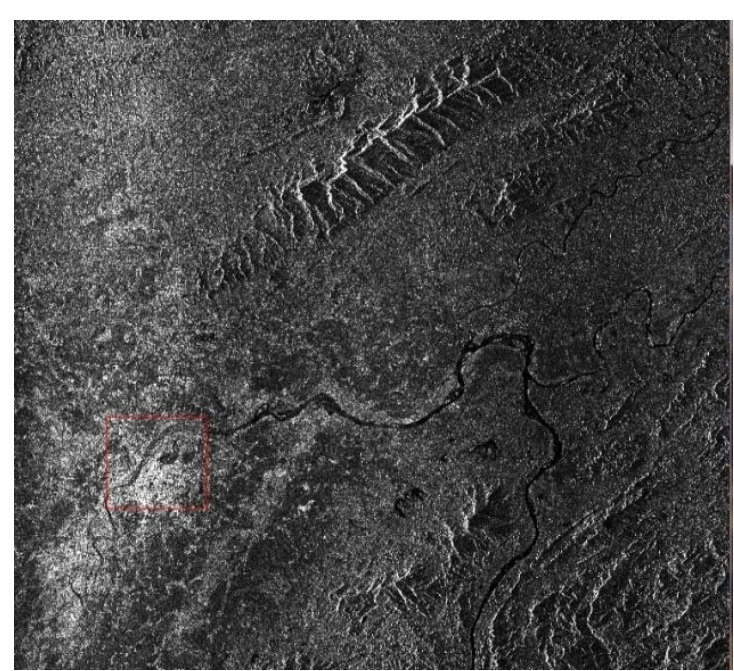

Fig. 3. Envisat ASAR image acquired on January $10^{\text {th }}, 2004$

\subsection{Processing}

Because the images are too big and there is so much vegetation that appear to be the main reason for lost coherence, therefore we selected a small area in the red frame which was focus on the urban area for processing. 
T.V. Anh, et al./Vietnam Journal of Earth Sciences 37 (2015)

With this data set, there were four pairs that created. The first pair for topography is the combination of 2003 December $6^{\text {th }}$ and 2004 January $10^{\text {th }}$. The second pair for deformation is combination of 2004 January $10^{\text {th }}$ and 2004 April $24^{\text {th }}$, the third and fourth pair are also for deformation purpose that are combination of 2004 January $10^{\text {th }}$ and 2004 May $29^{\text {th }}$ (thirdpair) and 2003 December $6^{\text {th }}$ and 2004 May $29^{\text {th }}$ (fourthpair). The baselines are $578.3 \mathrm{~m}, 181.9 \mathrm{~m}$, 194.1 and $774.04 \mathrm{~m}$ for topographic and 3 deformation pairs respectively as order in the table 1 . The coherence images of four pairs were illustrated in figure 4 . In this figure the bright color is high coherence and dark color is reverse. In three coherence images $(a, b, c)$ the high coherence were on the urban area where are less vegetation and water bodies than the outside. The fourth coherence image (d) was also the same with three ones above but it was much noisy thus we did not choose this pair for next processing.
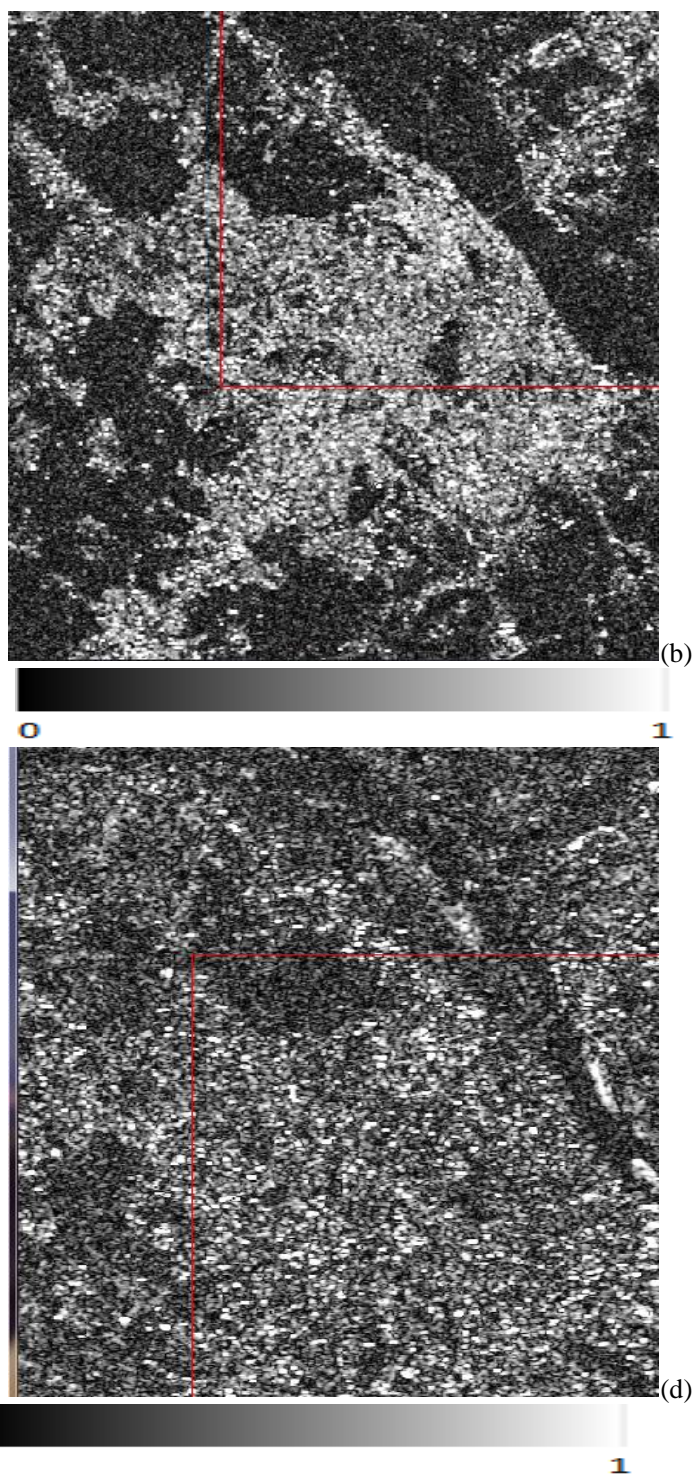

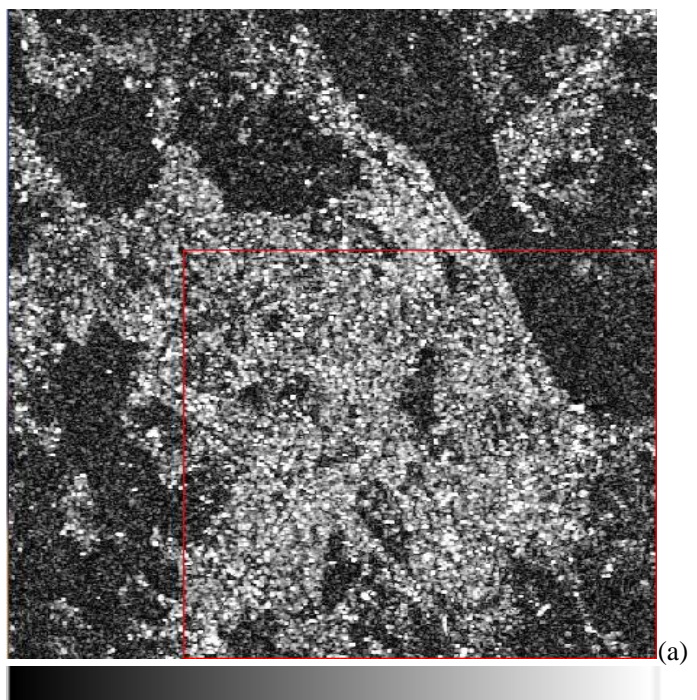

o

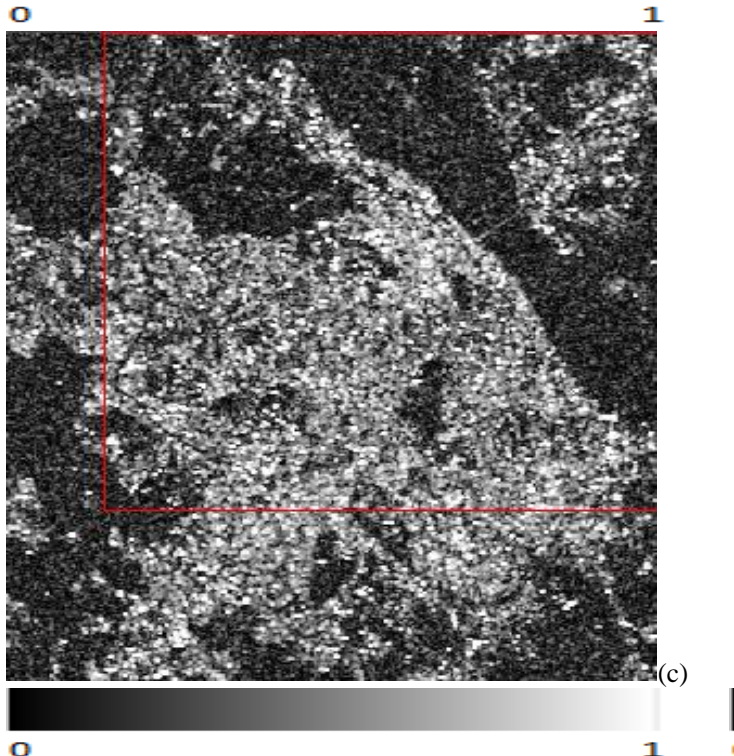

Fig. 4. Coherence images of four pairs with high coherence of bright color and low coherence of dark color, (a): (2003/12/06-2004/1/10), (b): (2004/1/10-2004/4/24), (c): (2004/1/10-2004/5/29), (d): (2003/12/06 - 2004/5/29) 


\section{Vietnam Journal of Earth Sciences 37 (2015) 344-354}

The data were processed and three subsidential phases from Two-pass and Three-pass method were created. The Two-pass method was combination of 2004 January $10^{\text {th }}$ and 2004 April $24^{\text {th }}\left(2^{\text {nd }}\right.$ pair $)$ and the pair of combination between 2004 January $10^{\text {th }} 2004$ May $29^{\text {th }}\left(3^{\text {rd }}\right.$ pair) with span of time was approximately 134 days and 169 days respectively. SRTM DEM 90m after conversing into ellipsoid was used for topographic phase creation. The subsidence was computed from this method is advantage than the other method that is needed only one pair for phase unwrapping (because phase unwrapping is difficult step to get accurate subsidence). The Three-pass method, the DEM pair was combination of 2003 December $6^{\text {th }}$ and 2004 January $10^{\text {th }}$, the deformation pair was the same with the Two-pass method chosen. With this method SRTM DEM $90 \mathrm{~m}$ was used for removing some errors caused from different elevations and for image geocoding.
The results were illustrated in Figure 5, it is noted that for the subsidence calculated by Twopass method is the $2^{\text {nd }}$ pair and $3^{\text {rd }}$ pair, which the $3^{\text {rd }}$ pair has bad result due to too low coherence. It has much noise in the downtown area except some subsidence sites are similar to the $2^{\text {nd }}$ pair, where marked with ellipses are manifestations of subsidence. Because of much noisy on the $3^{\text {rd }}$ pair we did not carry out further three-pass method with 1-3 pair, but only did for the $1-2$ pair. The results by Two-pass method of $2^{\text {nd }}$ pair and Threepass of 1-2 pair are good, thus we conducted a comparison between two outcomes from two methods. The outcomes from two methods were similar in the southwest area of the city, but were different in the northern part. This proves that there is certainly land subsidence in the southern area of the city, while the northern area near West Lake (Ho Tay) needs to be further examined.
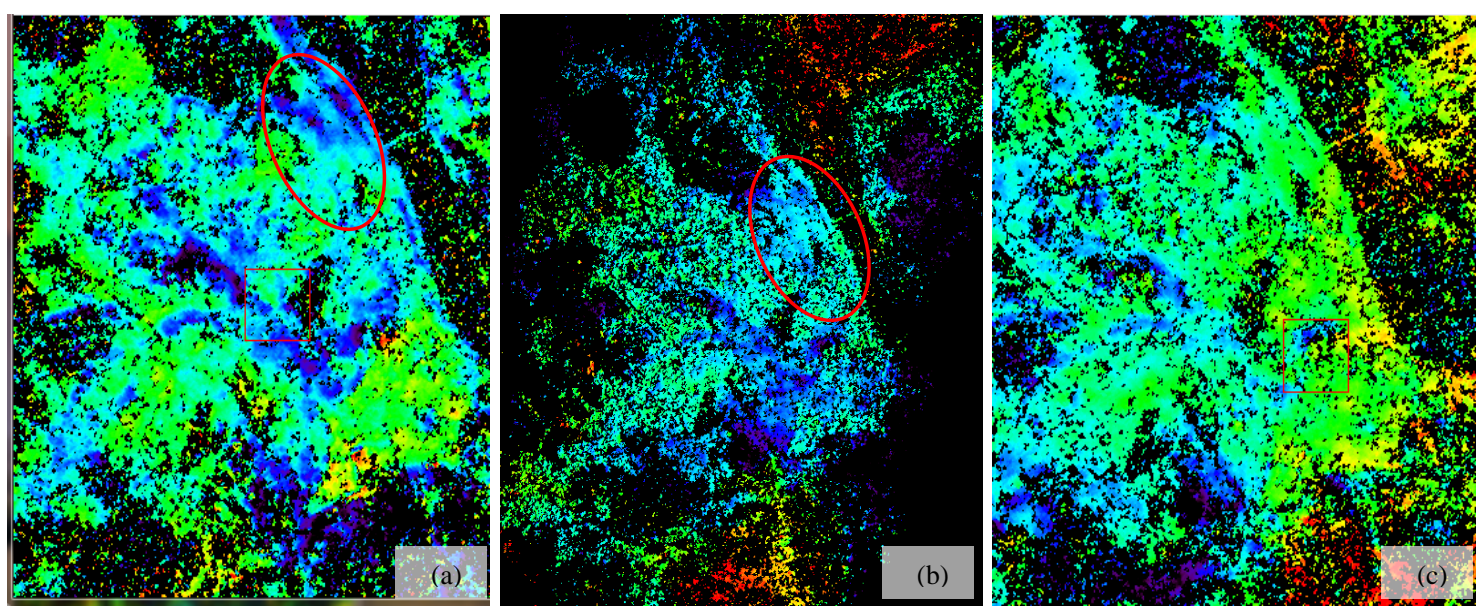

$-2 \mathrm{~cm}$

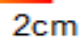

Fig. 5. Subsidence from Two-pass method of $2^{\text {nd }}$ and $3^{\text {rd }}$ pair (a, b) and Three-pass method from $2^{\text {nd }}$ pair and $1^{\text {st }}$ pair subtraction (c)

\section{Discussion}

If the results of the Two-pass method that used the Shuttle Radar Topography Mission SRTM DEM, were accurate and had less atmospheric affect, the outcomes of Two and Three-pass methods would be similar. However, because of the errors due to atmospheric conditions, clouds ... together with DEM errors the results may be different. As we have already known, SRTM DEM, made from SRTM in orbit for 11 days and generated DEM method, is interferometric SAR images, thus its accuracy is similar to the image that we use. But this DEM was generated in 2000, when building constructions were far fewer than in 2004. There have been significant changes in surface topography, so if we use this DEM (actually is digital surface model-DSM) as DEM at the time of 2003-2004 its error will occur in phase interferometry (equation 6). If we use the SRTM DEM as a reference DEM for accurate location and conduct geocoding and if any errors exist for 
T.V. Anh, et al./Vietnam Journal of Earth Sciences 37 (2015)

Three-pass it would be removed when we apply subtraction two phases to each other.

With the analysis we realized that the subsidence of Two-pass is distributed at many sites on the image, even northern areas near the Red River where subsidence was ignorable due to the water recharge ability of the Red River for ground water pumping station in this area (red circle on the figure $5(\mathrm{a}, \mathrm{b})$. In the southern areas of the city the subsidence was visible in many locations such as Tuong Mai, Linh Dam, Ha Dong. Figure 5 (b) illustrates the fourth pair with lower coherence compared with the other, thus this pair was referent use, and we would not analyze more using Three-pass for this pair. Figure 5(c) demonstrates the subsidence distribution of Three-pass method. For this method subsidence was found in southern city but in the northern area as near as the Red River, there was no subsidence observed. This demonstrates that the influence of errors caused by SRTM DEM made some virtual subsidence with Two-pass method.

To verify the coincidence of two methods we collected surveying data that were measured in the period from 2000 to 2013 (table 2). The benchmarks are situated at the ground water extraction wells of Hanoi. However, as shown in Table 2, the subsidence data was interrupted in 2004 to 2007 whereas Envisat ASAR images acquired during 2003-2004 period . In contrast, trend of subsidence in the benchmarks was visible at Ha Dinh, Luong Yen, Phap Van, Thanh Cong, Ngoc Ha during 2000-2003. The subsidence data from DInSAR with Two and Three-pass were compared with land subsidence data measured from above mentioned monitoring stations (Table 2). After overlaying the benchmarks to the subsidence images from Two-pass and Three-pass, we found that only two positions can determine the relationship between two types of subsidence detection that are Ha Dinh and Thanh Cong sites. When charting the data of these two benchmarks, we realized the trend of subsidence over time decreased in the period of 2000 and 2003 (Figure 6 ), suggesting that there has been a moderation in the exploitation of underground water in Hanoi. At the Ha Dinh and Thanh Cong sites, by using two methods of DInSAR acquired values of subsidence by Two and Three-pass are $9 \mathrm{~mm}$ and $8.5 \mathrm{~mm}$ respectively; while Ha Dinh showed subsidence of $5 \mathrm{~mm}$ and $4.7 \mathrm{~mm}$ in about three and half months between 2004 January $10^{\text {th }}$ and 2004 April $24^{\text {th }}$. Figure 7 illustrates Two-pass and Three-pass results overlaying the surveying points, but the subsidence values were rather similar at two sites. Because subsidence amount measured by land subsidence monitoring stations was an annual average, so after converting Two-pass and Threepass values into annual subsidence, the value was almost the same with two methods. The average subsidence of $24 \mathrm{~mm}$ and $23 \mathrm{~mm}$ acquired by Twoand Three- pass at Thanh Cong, while Ha Dinh was $13 \mathrm{~mm}$ by both methods.

Subsidence values

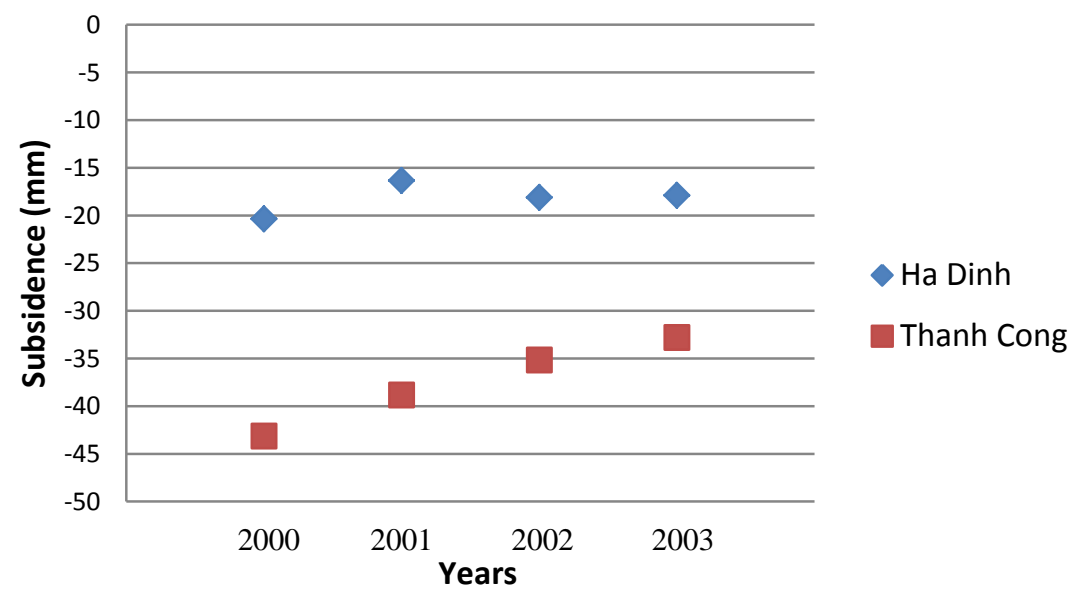

Fig. 6. The subsidence measured at Ha Dinh and Thanh Cong monitoring stations (2000-2003) 
Vietnam Journal of Earth Sciences 37 (2015) 344-354

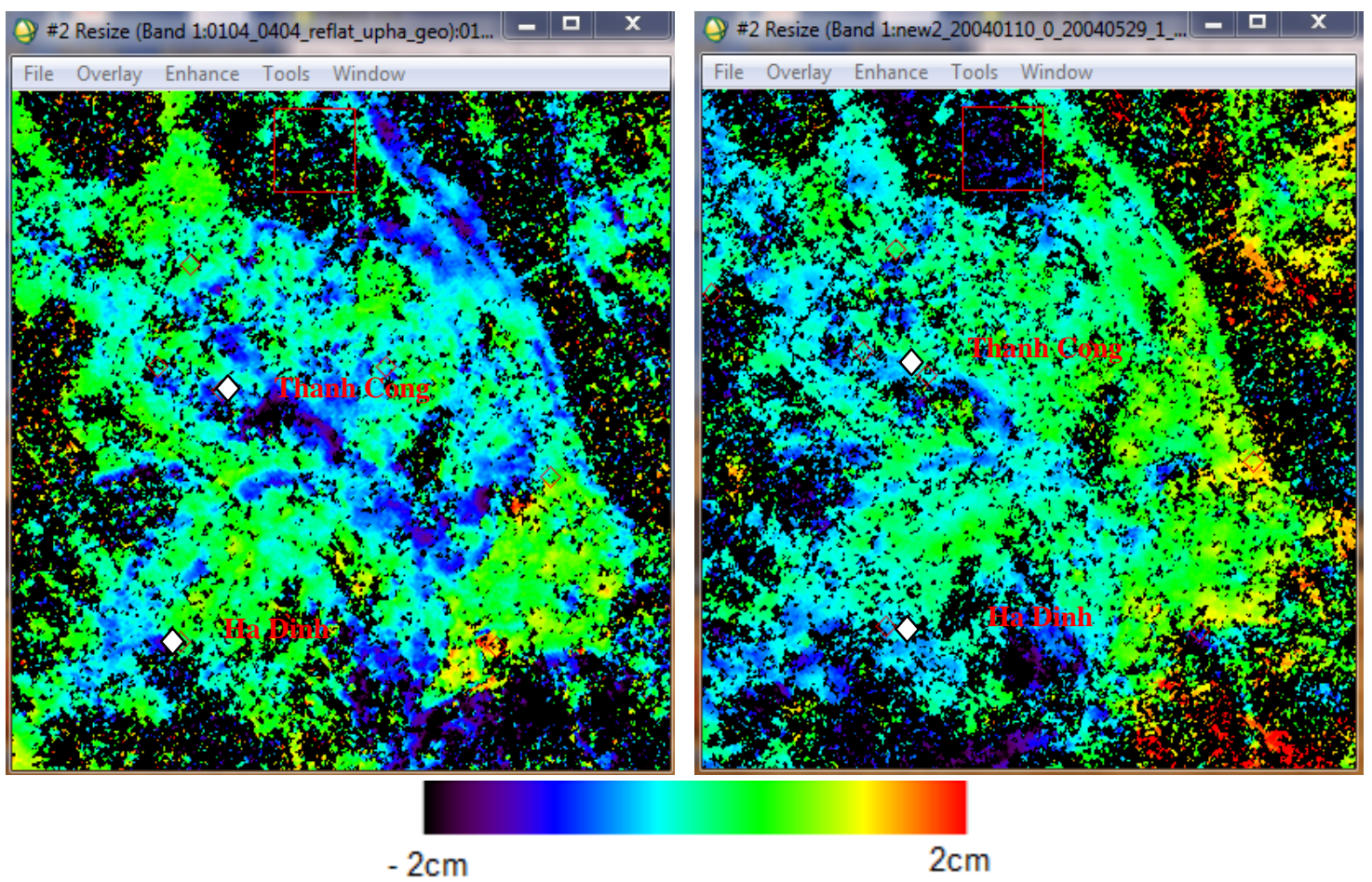

Fig. 7. Two-pass and Three-pass results overlaid with surveying points

If the subsidence measured from DInSARis charted as the year of 2004 to combine with the data acquired by monitoring stations between 2000 and 2003), we found that the subsidence trend is linear (Figure 8). We thus conclude that with
DInSAR method which used Envisat ASAR data set, the distribution of subsidence at Thanh Cong and $\mathrm{Ha}$ Dinh sites is correlated with the data measured by monitoring stations.

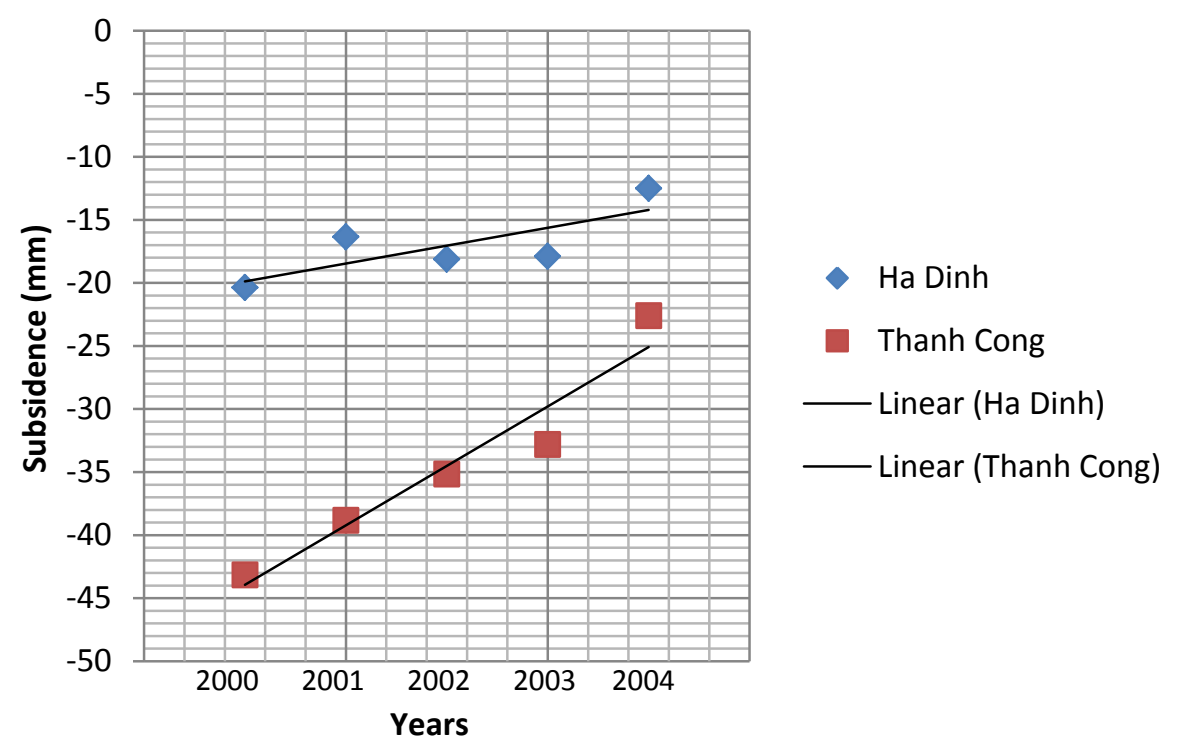

Fig. 8. Subsidence charting of Ha Dinh and Thanh Cong sites by leveling survey (2000-2003) and DInSAR (2004) 
T.V. Anh, et al./Vietnam Journal of Earth Sciences 37 (2015)

\section{Conclusions}

Our major conclusions are as follows:

The most advantage in using the DInSAR method is that the cost for images are reasonable, for it needs only 2 to 3 images suitable for areas which have limited number of images. However, the disadvantage of this method is that there are a number of factors effecting the accuracy of the outcome, including the atmospheric affect, the baseline length, and especially the effect of DEM accuracy in Two- pass method. The DEM errors may add or subtract phase and create the virtual subsidence or uplift, as our experiment in Hanoi, where the northern area near the Red River was a typical example.

The subsidence data acquired at Ha Dinh and Thanh Cong sites by land monitoring stations were comparable to the results of two DInSAR methods although there was a minor change of subsidence observed for 2004 at the two sites. The subsidence value acquired by monitoring stations tends to decrease with time as observed for Ha Dinh from 2008 to 2012, respectively, of $-10.82 \mathrm{~mm}$, $-8.68 \mathrm{~mm},-9.5 \mathrm{~mm},-6.73 \mathrm{~mm}$, and $-4.03 \mathrm{~mm}$ or for Thanh Cong, respectively, of $-33.39 \mathrm{~mm}$, $-27.19 \mathrm{~mm},-26.59 \mathrm{~mm},-23.91 \mathrm{~mm}$, and $-20.81 \mathrm{~mm}$ ). It proved that the subsidence trend at the two sites is suitable with our experiment.

\section{Acknowledgments}

The research was implemented in the frame work of Viet Nam national science project DTDL.2012-T/28. We also would like to thank ESA for providing Envisat Asar images used in this research.

\section{References}

Colesanti, C., Ferretti, A., Novali, F., Prati, C. and Rocca, F., 2003: SAR monitoring of progressive and seasonal ground Deformation using the permanent scatterers technique, IEEE Transaction on Geoscience and Remote Sensing, 41, 1685-1701.

Dehls, J.F., Basilico, M. and Colesanti, C., 2002: Ground deformation monitoring in the Ranafjord area of Norway by means of the permanent scatterers technique, 23th International Geoscience and Remote Sensing Symposium (Expanded Abstract), Toronto, June 24-28, p. 203-207.
Ferretti, A., Prati, C. and Rocca, F., 2000: Nonlinear subsidence rate estimation using permanent scatterers in differential SAR interferometry, IEEE Transaction on Geoscience and Remote Sensing, 38, 2202-2212.

Gabriel, A.K., Goldstein, R.M. and Zebker, H. A., 1989: Mapping small elevation changes over large areas: Differential Radar Interferometry, Journal of Geophysical Research, 94 (B7), pp. 9183-9191.

Goldstein, R. M., Engelhardt, H., Kamb, B. and Frolich, R.M., 1993: Satellite radar interferometry for monitoring ice sheet motion: Application to an Antarctic icestream.Science, 262, pp. 1525-1530.

Graham, L.C., 1974: Synthetic Interferometer Radar for Topographic Mapping, Proceedings of the IEEE, 62(6), pp. 763-768.

Gray, A.L., Mattar, K.E. and Sofko, G., 2000: Influence of ionosphereic electron density fluctuations on satellite radar interferometry, Geophysical Research Letters, 27(10), pp. 1451-1454.

Hanssen, R.F. and Feijt, A., 1996: A first Quantitative Evaluation of Atmospheric Effects on SAR Interferometry, Proceedings of the 'Fringe 96' Workshop on ERS SAR Interferometry, Zurich, Switzerland, pp. 277-282.

Hooper, A., Segall, P., and Zebker, H., 2007: Persistent scatterer interferometric synthetic aperture radar for crustal deformation analysis, with application to Volcan Alcedo, Galapagos, Journal of Geophysical Research, 112, 7, B07407, doi:10.1029/2006JB004763.

K. V. Dang, C. Doubre, C. Weber, F. Masson, and N. Gourmelen, 2013: Recent land subsidence caused by the rapid urban development in the Hanoi urban region (Vietnam) using ALOS.

InSAR data, journal Natural Hazards and Earth System Sciences (NHESS).

Kampes B. and Usai S., The Delft Object-oriented Radar Interferometric software, Proc. 2nd Int. Symp.Operational Rem. Sensing, ITC, Enschede, The Netherlands, 16th August 1999., 4 pages (CD-ROM).

Massonnet, D., Rossi, M., Carmona, C., Adragna, F., Peltzer, G., Feigi, K. and Rabaute, T., 1993: The displacement field of the Landers earthquake mapped by radar interferometry, Nature, 364, pp.138-142.

Massonnet, D. and Feigl, K.L., 1998: Radar interferometry and its application to changes in the earth's surface, Reviews of Geophysics, 36(4), pp.441-500. 


\section{Vietnam Journal of Earth Sciences 37 (2015) 344-354}

Nhan Pham Quy, et al., 2008: Research and assessmen potential ground water resource of Hanoi area, degeneration groundwater reserve and quality, built-up orientation strategy for reasonable exploitation water, protection environment for sustainable development capital. Final Report. Hanoi research project code: 010-04/092008-2.

Price, E. J and Sandwell, D. T., 1998: Phase gradient approach to stacking interferograms,Journal of Geophysical Research, 103(B12), pp. 30183-30204.

Rott, H., Mayer, C. and Siegel, A., 2000: On the operational potential of SAR interferometry for monitoring mass movements in Alpine areas,Proceedings of EUSAR2000, Munich, Germany, pp.43-46.

Sowter, A. \& Warren, M., 2005: Reducing the DEM Error Effect in Differential Interferometry, Fringe 2005 Workshop, Proceedings of the Conference.

Tran Van Anh, Shinji Masumoto, KiyojiShiono and VenkateshRaghavan, 2007: Spatial distribution of subsidence in Hanoi detected by JERS-1 SAR interferometry, Journal of GeoInformatics-Japan, Vol. 18, no.1.

Wegmüller, U., Werner, C., Wiesmann, A. and Strozzi, T., 2003: Interferometricpoint target analysis with JERS-1 L-band SAR data, IGARSS'03, Toulouse, France.

Zebker, H.A. and Goldstein, R.M., 1986: Topographic mapping from interferometricsynthetic aperture radar observations, Journal of Geophysical Research, 91(B5), pp. 4993-4999.

Zebker, H. A. and Villasenor, J., 1992: Decorrelation in interferometric radar echoes,IEEE Transactions on Geoscience and Remote Sensing, 139(2), pp. 88-97.

Zebker, H. A., Rosen, P. A., Goldstein, R. M., Gabriel, A. and Werner, C. L., 1994: On the derivation of coseismic displacement fields using differential radar interferometry: The Landers earthquake, Journal of Geophysical Research, 99(B), pp.1961-1967.

Zebker, H.A., Rosen, P.A. and Hensley, S., 1997: Atmospheric effects ininterferometricsynthetic aperture radar surface deformation and topographic maps, Journal of Geophysical Research, 102(B4), pp.7547-7563. 